\title{
Prospective association between dietary magnesium intake and physical performance in older women and men
}

\author{
Lucía Arias-Fernández ${ }^{1,2}$ - Ellen A. Struijk ${ }^{2}$ Francisco Félix Caballero² $\cdot$ Rosario Ortolá $^{2}$ Esther García-Esquinas ${ }^{2}$. \\ Fernando Rodríguez-Artalejo ${ }^{2,3} \cdot$ Esther Lopez-Garcia $^{2,3} \cdot$ Alberto Lana $^{1,2}$
}

Received: 23 September 2021 / Accepted: 11 January 2022 / Published online: 4 February 2022

(c) The Author(s) 2022

\begin{abstract}
Purpose Magnesium is a profuse intracellular cation with a key role in muscle function and cellular senescence. The aim was to examine the prospective association between 5 year changes in dietary intake of magnesium and changes in physical performance among older men and women.

Methods Prospective study conducted over 863 community-dwellers aged $\geq 65$ years from the Seniors-ENRICA cohort (Spain). In 2012 and 2017, a validated computerized face-to-face diet history was used to record the consumption of up to 880 foods. From these data, we estimated changes in dietary magnesium intake. The Short Physical Performance Battery (SPPB) was also conducted in both time points and we obtained changes in the score during follow-up, with positive values indicating physical performance improvement.

Results Over 5 years of follow-up, an increase in magnesium intake was associated with an increment in the SPPB score among older women [multivariate $\beta(95 \%$ confidence interval): $1.01(0.49 ; 1.52), p$-trend: 0.001 ]. In addition, changes from non-adherence to adherence to both estimated average requirement and recommended dietary allowance during follow-up period were associated with an increment in SPPB score among older women $[1.14(0.36 ; 1.92)$ and $0.84(0.22 ; 1.47)$, respectively]. No significant associations between changes in magnesium intake and changes in SPPB score were observed in men. Conclusions Both increase of magnesium intake and change from non-adherence to adherence to dietary reference magnesium intake was prospectively associated with better physical performance among older women, but not among men.
\end{abstract}

Keywords Diet $\cdot$ Magnesium $\cdot$ Physical functional performance $\cdot$ Older adults

$\begin{array}{ll}\text { Abbreviations } \\ \mathrm{Mg} & \text { Magnesium } \\ \mathrm{SPPB} & \text { Short Physical Performance Battery } \\ \mathrm{BMI} & \text { Body mass index } \\ \text { EAR } & \text { Estimated Average Requirement } \\ \text { RDA } & \text { Recommended Dietary Allowance } \\ \text { EFSA } & \text { European Food Safety Authority }\end{array}$

Alberto Lana

lanaalberto@uniovi.es

1 Department of Medicine. School of Medicine and Health Sciences, School of Medicine and Health Sciences, Universidad de Oviedo/ISPA, Calle Julián Clavería, s/n, 33006 Oviedo, Spain

2 Department of Preventive Medicine and Public Health, School of Medicine, Universidad Autónoma de Madrid-IdiPaz and CIBERESP (CIBER of Epidemiology and Public Health), Madrid, Spain

3 IMDEA-Food Institute, CEI UAM+CSIC, Madrid, Spain
AI Adequate intake

NHANES National Health and Nutrition Examination Survey

\section{Introduction}

Magnesium $(\mathrm{Mg})$ is a very abundant intracellular cation which sustains several basic cellular processes. Among older adults, $\mathrm{Mg}$ deficiency is frequent because of the age-related decline in dietary intake combined with alterations in the $\mathrm{Mg}$ absorption/excretion balance [1]. There is evidence linking the $\mathrm{Mg}$ deficiency to cellular senescence and to an accelerated aging phenotype [2]. Specifically, given that $\mathrm{Mg}$ exerts a key role in muscle function, an inadequate dietary intake could have a negative impact on physical performance in the old age $[3,4]$.

Slowing the progressive decline in physical performance is one of the keys strategies to achieve healthy aging. To 
the date, in addition to the fact that studies addressing the association between $\mathrm{Mg}$ and physical performance among older adults are scarce and conflicting, it is unclear which method is the most ideal to assess the association. A crosssectional analysis using baseline data from the InCHIANTI study (aging in the Chianti area, Italy) showed, for the first time, that serum $\mathrm{Mg}$ concentration was an independent determinant of muscle performance in older adults [5]. But, given there is controversy about whether serum $\mathrm{Mg}$ is an appropriate proxy of $\mathrm{Mg}$ stores or not, other studies used dietary $\mathrm{Mg}$ intake to address the association, which can also lead to more practical conclusions for clinical counselling and public health interventions [6]. Using a dietetic approach, Veronese et al. found that a daily $\mathrm{Mg}$ supplementation improved the physical performance of healthy older women who participated in a parallel randomized controlled trial [7]. Nevertheless, a recent study found no effect of $\mathrm{Mg}$ intake on changes in physical performance [8]. Moreover, none of these studies accounted for sex differences, although women could be more susceptible to $\mathrm{Mg}$ deficiencies than men, because of their higher frequency of musculoskeletal disorders, including osteoporosis, which is known to limit Mg exchange between bone and blood [7, 9].

Therefore, our study aimed to assess the prospective association between 5 year changes in dietary intake of $\mathrm{Mg}$ and changes in physical performance among older men and women.

\section{Methods}

\section{Study design and participants}

This was a prospective study using data from the SeniorsENRICA cohort (Spain), whose methods have been reported elsewhere $[10,11]$. This cohort included community-dwelling adults aged 60 years and older, who were recruited in 2008-10. At baseline, information about lifestyle, health status, morbidity and use of health services was collected with a standardized phone interview. Then, two home visits were conducted to perform a physical examination and to obtain data on habitual diet. In 2012 and 2017, two subsequent waves of data collection were performed, using the same procedures, to update baseline information. Given that physical performance, as measured by the Short Physical Performance Battery (SPPB) [12], was first assessed in 2012, analyses for this work were conducted with the 2519 participants in 2012 who were followed-up to 2017.

Written informed consent was given by all study participants. The Seniors-ENRICA cohort was approved by the Clinical Research Ethics Committee of the $\mathrm{La} \mathrm{Paz}$ University Hospital in Madrid (registration number: 2144).

\section{Study variables}

\section{Diet history and mineral intake}

In 2012 and 2017, a validated computerized face-to-face diet history was used to assess habitual food consumption during the previous year [13]. This instrument included 880 foods and beverages as well as sets of photographs to help participants estimate serving sizes. Daily Mg intakes were estimated using standard Spanish food composition tables [14]. Mineral intake through supplements was not considered due to its low use $(<1 \%)$ and the lack of data on the specific type consumed. The validity of the diet assessment was evaluated by comparing information obtained using the diet history with seven 24 -h recalls over a period of 1 year among a subsample of participants; the Pearson correlation coefficient was moderately good for $\mathrm{Mg}$ intake ( $r=0.46)$ [13]. Intake of $\mathrm{Mg}$ was adjusted for total energy using the residuals method [15].

\section{Physical performance}

The SPPB was used, according to protocol of the National Institute on Aging [12], to assess physical function in 2012 and 2017. The SPPB comprises three standardized timed components: standing balance, gait speed and chair stand. To assess the balance, participants were asked to stand in three progressively difficult positions for $10 \mathrm{~s}$ each: feet side by side, semi-tandem, and full-tandem position. Then, gait speed was measured as the shortest time (seconds) of two consecutive walks at a normal pace along a corridor of $2.44 \mathrm{~m}$ long ( 8 -foot walk), using their assistive device if needed. Finally, the chair-stand test was performed by asking participants to stand up from a chair and sit down five times with no help from their arms. Each of these three tests was scored from 0 (inability to perform the task) to 4 (highest level of performance). Therefore, a global SPPB score was created by adding each component test score, ranging from 0 to 12 (best performance).

\section{Other variables}

Data on potential confounders of the study association were also collected in 2012 and 2017. We assessed sociodemographic characteristics (sex, age, education level) and health behaviours, including smoking, alcohol consumption, and time spent watching TV as a proxy of sedentariness [11]. Recreational physical activity, measured in metabolic equivalents hours per week (MET-h/w), 
was assessed with the validated questionnaire used in the EPIC-Spain cohort study [16].

Data on morbidity were also collected. Body Mass Index (BMI) was calculated as measured weight $(\mathrm{kg})$ divided by square height $(\mathrm{m})$, and obesity was defined as $\mathrm{BMI} \geq 30 \mathrm{~kg} / \mathrm{m}^{2}$. Diabetes was defined as fasting plasma glucose $\geq 126 \mathrm{mg} / \mathrm{dl}$ or taking antidiabetic therapy [17]. Blood pressure was measured under standardized conditions [18], and hypertension was defined as systolic/diastolic blood pressure $\geq 140 / \geq 90 \mathrm{mmHg}$ or being under hypertensive drug treatment. Finally, hypercholesterolemia was defined as cholesterol $\geq 200 \mathrm{mg} / \mathrm{dl}$ or undergoing lipid-lowering treatment. Participants also reported the following physiciandiagnosed diseases: cardiovascular disease (heart failure, heart attack or stroke), musculoskeletal disease (arthritis, osteoarthritis or hip fracture) and cancer.

\section{Statistical analysis}

Of the 2519 participants in the Seniors-ENRICA in 2012, 1185 were lost to follow-up and 196 died up to 2017. Also, we excluded individuals lacking data on $\mathrm{Mg}$ intake $(n=263)$, implausible low or high energy intake values $(n=2)$ or without information on any of the rest of study variables $(n=10)$. Therefore, the analyses were conducted with 863 individuals (424 men and 439 women).

We used multivariable linear regression to study the associations between changes in $\mathrm{Mg}$ intake and changes in the SPPB score from 2012 to 2017 . The dependent variable was the continuous change in SPPB score, resulting from the subtraction of 2017 minus 2012 values. The main independent variables were sex-specific tertiles of $\mathrm{Mg}$ intake change between 2012 and 2017: the first tertile reflected an intake decrease, the second tertile a small intake change, and the third tertile an intake increase. First, residual plots were used to check the assumption of linearity and homoscedasticity. Then, two regression models were fitted with the second tertile as reference: (1) the first model was adjusted for baseline SPPB score, age, educational level, baseline physical activity, smoker status, BMI, TV-watching and alcohol intake; (2) the second model was additionally adjusted for baseline morbidity, including diabetes, hypertension, hypercholesterolemia, cardiovascular disease, cancer and musculoskeletal disease. The linear dose-response association ( $p$ value for trend) was tested by modelling $\mathrm{Mg}$ intake as a continuous variable. We also repeated the analyses using a $1 \mathrm{SD}$-increment of $\mathrm{Mg}$ intake change during the 5-year period as the independent variable. To assess the consistency of results, the analyses were stratified by physical activity, musculoskeletal disease, obesity, cardiometabolic disease (diabetes and cardiovascular disease) and alcohol intake; likelihood-ratio tests comparing models with and without interactions terms were used to assess whether results varied across strata.

In addition, we classified participants according to their level of compliance with the current US dietary reference intake for $\mathrm{Mg}$ [19], using both the estimated average requirement (EAR) ( $\geq 350 \mathrm{mg} / \mathrm{d}$ for men and $\geq 265 \mathrm{mg} / \mathrm{d}$ for women) and the recommended dietary allowance (RDA) ( $\geq 420 \mathrm{mg} / \mathrm{d}$ for men and $\geq 320 \mathrm{mg} / \mathrm{d}$ for women). According to these cut-off points, we defined four categories of participants: non-compliers both in 2012 and 2017; those who moved from non-compliance in 2012 to compliance in 2017; those who moved from compliance in 2012 to noncompliance in 2017; and compliers both in 2012 and 2017. Then, we fitted the same regression models described above, using non-compliers in both time points as the reference group. Moreover, to aim for consistency and generalization, we repeated the analyses using the cut-off points from the European Food Safety Authority (EFSA). Given that the EFSA considers that EAR or RDA for Mg cannot be derived for adults, we used its defined adequate intake (AI) ( $\geq 350 \mathrm{mg} / \mathrm{d}$ for men and $\geq 300 \mathrm{mg} / \mathrm{d}$ for women) [20].

Sex differences in the association between changes in $\mathrm{Mg}$ intake and SPPB scores were tested with likelihood-ratio tests, which compared models with and without cross-product interaction terms. Given that we found a sex interaction ( $p$ for interaction $=0.02$ in the fully-adjusted model) in main analyses, all results are presented for men and women separately.

Analyses were performed with the STATA software, 15.0 version (Stata Corp, College Station, TX). This manuscript follows the Strengthening the Reporting of Observational Studies in Epidemiology (STROBE) recommendations.

\section{Results}

Table 1 shows the main characteristics of participants according to sex and year of data collection. Throughout the follow-up period, there was a decrease in tobacco consumption, daily energy intake and BMI for both sexes. Likewise, the daily intake of $\mathrm{Mg}$ was reduced, leading to a lower percentage of compliance for EAR and RDA recommendations in 2017 compared to 2012. Lastly, the prevalence of chronic diseases was higher in 2017 than in 2012 for both men and women. Over the 5-year follow-up period, we identified $453(52.5 \%)$ participants with minimal or no changes in the SPPB score, $202(23.4 \%)$ with a decrease and $208(24.1 \%)$ with an increase in the score. As a result, there was only a slight decrease in the mean SPPB score between 2012 and 2017 in both men and women.

Table 2 shows the associations between changes in daily Mg intake and changes in the SPPB score between 2012 and 2017, overall and by sex. Compared to women with small 
Table 1 Characteristics of participants at baseline and at the end of follow-up in lifestyle, magnesium intake, morbidity and SPPB score, by sex

\begin{tabular}{|c|c|c|c|c|c|c|c|}
\hline & & \multicolumn{3}{|c|}{ Women $(n=439)$} & \multicolumn{3}{|c|}{ Men $(n=424)$} \\
\hline & & 2012 & 2017 & $p$ value $^{\mathrm{a}}$ & 2012 & 2017 & $p$ value $^{\mathrm{a}}$ \\
\hline Age, year & & $70.9(5.36)$ & $75.6(5.24)$ & N/A & $70.0(5.38)$ & $74.8(5.33)$ & N/A \\
\hline Primary education or less, $n(\%)$ & & $254(57.9)$ & - & N/A & $162(38.2)$ & - & N/A \\
\hline Physical activity, METs-h/w & & $18.8(12.1)$ & - & N/A & $25.8(17.0)$ & - & N/A \\
\hline TV-watching, h/d & & $19.6(10.9)$ & $20.4(11.9)$ & 0.160 & $17.1(9.66)$ & $19.3(11.6)$ & $<0.001$ \\
\hline Current smokers, $n(\%)$ & & $17(3.87)$ & $16(3.64)$ & 0.01 & $59(13.9)$ & $43(10.1)$ & $<0.001$ \\
\hline Alcohol intake, $\mathrm{g} / \mathrm{d}$ & & $4.36(8.34)$ & $3.66(8.49)$ & 0.05 & $15.6(16.6)$ & $14.1(15.9)$ & 0.04 \\
\hline Energy intake, kcal/d & & $1868(387)$ & $1,692(290)$ & $<0.001$ & $2238(460)$ & $2029(363)$ & $<0.001$ \\
\hline BMI, $\mathrm{kg} / \mathrm{m}^{2}$ & & $28.4(4.89)$ & $27.4(4.82)$ & $<0.001$ & $28.5(3.65)$ & $27.9(3.63)$ & $<0.001$ \\
\hline Mg intake, $\mathrm{mg} / \mathrm{d}$ & & $332(114)$ & $300(76.3)$ & $<0.001$ & $360(95.8)$ & $339(77.8)$ & $<0.001$ \\
\hline \multicolumn{8}{|l|}{ Mg intake compliance } \\
\hline & EAR, $n(\%)$ & $310(70.6)$ & $271(64.7)$ & $<0.001$ & $187(44.1)$ & $156(36.8)$ & $<0.001$ \\
\hline & RDA, $n(\%)$ & $187(42.6)$ & $153(34.9)$ & $<0.001$ & $81(19.1)$ & $61(14.4)$ & $<0.001$ \\
\hline \multicolumn{8}{|l|}{ Morbidity } \\
\hline Diabetes, $n(\%)$ & & $56(12.8)$ & $71(16.2)$ & $<0.001$ & $94(22.2)$ & 109 (25.7) & $<0.001$ \\
\hline Hypertension, $n(\%)$ & & $245(55.8)$ & $275(62.6)$ & $<0.001$ & $240(56.6)$ & $273(64.4)$ & $<0.001$ \\
\hline Hypercholesterolemia, $n(\%)$ & & $231(52.6)$ & $263(59.9)$ & $<0.001$ & $200(47.1)$ & $223(52.6)$ & $<0.001$ \\
\hline Cardiovascular $^{\mathrm{b}}, n(\%)$ & & $16(3.64)$ & $32(7.29)$ & $<0.001$ & $25(5.90)$ & $39(9.20)$ & $<0.001$ \\
\hline Cancer, $n(\%)$ & & $7(1.59)$ & $13(2.96)$ & $<0.001$ & $8(1.89)$ & $27(6.37)$ & $<0.001$ \\
\hline Musculoskeletal $^{\mathrm{c}}, n(\%)$ & & $256(58.3)$ & $327(74.5)$ & $<0.001$ & $146(34.4)$ & $207(48.8)$ & $<0.001$ \\
\hline SPPB, score & & $8.46(2.15)$ & $8.32(2.72)$ & 0.23 & $9.31(2.03)$ & $9.27(2.45)$ & 0.72 \\
\hline
\end{tabular}

Note for continuous variables, mean value (standard deviation) is reported

$S P P B$ Short Physical Performance Battery test, $M E T$ metabolic equivalent, TV Television, EAR estimated average requirement, $R D A$ recommended dietary allowance

a Paired $t$-test for continuous variables and McNemar's test for categorical variables were used for statistical comparison

${ }^{\mathrm{b}}$ Cardiovascular diseases include heart failure, heart attack and stroke

${ }^{\mathrm{c}}$ Musculoskeletal diseases include arthritis, osteoarthritis and hip fracture

changes in $\mathrm{Mg}$ intake (tertile 2), those who increased their intake over follow-up (tertile 3) showed beneficial changes in the SPPB score. Specifically, a mean increase in Mg intake of $44.2 \mathrm{mg} / \mathrm{d}$ from 2012 to 2017 was associated with an increment of 1.01 points (95\% confidence interval: 0.49; 1.52 ) in the SPPB score; the corresponding value for a 1-SD increase in $\mathrm{Mg}$ intake was $0.28(0.01 ; 0.47)$ points. However, no association was observed for men. The study associations did not significantly vary across predefined strata (all $p$ for interaction $>0.05$ ), though the association tended to be stronger in women with low physical activity, with musculoskeletal disease, without obesity or cardiometabolic disease and abstainers (Supplementary Table 1).

Table 3 shows the associations between changes in adherence to the $\mathrm{Mg}$ reference intake and changes in SPPB score from 2012 to 2017 stratified by sex. In general, women who became compliant with the EAR between 2012 and 2017 had an increased SPPB score, in comparison with those who were no-compliant in both time points. Specifically, an improvement in EAR adherence (from non-compliance to compliance) was associated with a $1.14(95 \%$ CI 0.36; 1.92) point increase in SPPB. Also, an improvement in the adherence to RDA (from non-compliance to compliance) was associated with an increase of $0.84(0.22 ; 1.47)$ points on the score in women. Again, no associations were observed in men. Similar results were observed when we used the AI from EFSA to define cut-off points for $\mathrm{Mg}$ intake recommendations (Supplementary Table 2).

\section{Discussion}

In this prospective study of community-dwelling older adults followed over a 5-year period, an increase of dietary $\mathrm{Mg}$ intake was associated with an improvement of physical performance, assessed by the SPPB, in women but not in men. Consistently, a change from non-compliance to compliance with the reference intake resulted in a better SPPB score among women. 
Table 2 Changes in the SPPB score (95\% confidence interval) between 2012 and 2017 according to sex-specific tertiles ${ }^{\mathrm{a}}$ of change in dietary magnesium intake between 2012 and 2017 , overall and by sex

\begin{tabular}{|c|c|c|c|c|c|}
\hline & $\begin{array}{l}\text { Tertile } 1 \\
\text { (intake decrease) }\end{array}$ & $\begin{array}{l}\text { Tertile } 2 \\
\text { (intermediate change) }\end{array}$ & $\begin{array}{l}\text { Tertile } 3 \\
\text { (intake increase) }\end{array}$ & $p$-trend & $\begin{array}{l}\text { Per 1-SD increase } \\
\text { during } 5 \text { year period }\end{array}$ \\
\hline \multicolumn{6}{|l|}{ Overall } \\
\hline Participants, $n(\%)$ & $289(33.5)$ & $287(33.3)$ & $287(33.2)$ & & \\
\hline Change in $\mathrm{Mg}$ intake, $\mathrm{mg} / \mathrm{d}$ & $-109.6(66.7)$ & $-22.8(49.1)$ & $54.5(49.2)$ & & \\
\hline Multivariable model $1^{\mathrm{c}}$ & \multicolumn{2}{|c|}{$0.03(-0.32 ; 0.39) \operatorname{Ref}$} & $0.40(0.05 ; 0.76)$ & 0.042 & $0.13(-0.02 ; 0.27)$ \\
\hline Multivariable model $2^{\mathrm{d}}$ & \multicolumn{2}{|c|}{$0.04(-0.31 ; 0.39) \operatorname{Ref}$} & $0.43(0.07 ; 0.78)$ & 0.034 & $0.13(-0.02 ; 0.28)$ \\
\hline \multicolumn{6}{|l|}{ Women } \\
\hline Participants, $n(\%)$ & $147(33.5)$ & $146(33.3)$ & $146(33.3)$ & & \\
\hline Change in $\mathrm{Mg}$ intake, $\mathrm{mg} / \mathrm{d}$ & $-130.4(76.6)$ & $-30.1(15.4)$ & $44.2(48.5)$ & & \\
\hline Multivariable model $1^{\mathrm{c}}$ & \multicolumn{2}{|c|}{$0.11(-0.40 ; 0.62) \operatorname{Ref}$} & $1.00(0.48 ; 1.51)$ & 0.001 & $0.34(0.13 ; 0.56)$ \\
\hline Multivariable model $2^{\mathrm{d}}$ & \multicolumn{2}{|c|}{$0.09(-0.41 ; 0.61) \operatorname{Ref}$} & $1.01(0.49 ; 1.52)$ & 0.001 & $0.35(0.14 ; 0.57)$ \\
\hline \multicolumn{6}{|l|}{ Men } \\
\hline Participants, $n(\%)$ & $142(33.5)$ & $141(33.3)$ & $141(33.3)$ & & \\
\hline Change in $\mathrm{Mg}$ intake, $\mathrm{mg} / \mathrm{d}$ & $-88.05(45.8)$ & $-15.2(15.3)$ & $65.2(47.7)$ & & \\
\hline Multivariable model $1^{\mathrm{c}}$ & \multicolumn{2}{|c|}{$0.02(-0.17 ; 0.50) \operatorname{Ref}$} & $-0.16(-0.65 ; 0.34)$ & 0.494 & $-0.11(-0.32 ; 0.09)$ \\
\hline Multivariable model $2^{\mathrm{d}}$ & \multicolumn{2}{|c|}{$0.05(-0.44 ; 0.54) \operatorname{Ref}$} & $-0.09(-0.59 ; 0.41)$ & 0.592 & $-0.10(-0.30 ; 0.11)$ \\
\hline
\end{tabular}

SPPBShort Physical Performance Battery test

${ }^{a}$ Sex-specific tertile cut-points were -59.8 and $-5.99 \mathrm{mg} / \mathrm{d}$ in women and -42.6 and $11.6 \mathrm{mg} / \mathrm{d}$ in men for magnesium

${ }^{\mathrm{b}} 1$-SD increase $=89.2 \mathrm{mg} / \mathrm{d}$ in women and $73.9 \mathrm{mg} / \mathrm{d}$ in men

${ }^{\mathrm{c}}$ Adjusted for baseline SPPB score (tertiles of score), age $(<70,70-79, \geq 80 \mathrm{y})$, educational level (primary, secondary, university) and physical activity (tertiles of METs-h/w), smoking status (current, former, never), BMI (tertiles of $\mathrm{kg} / \mathrm{m}^{2}$ ), TV-watching (tertiles of h/wk) and alcohol intake (tertiles of $\mathrm{g} / \mathrm{d}$ )

${ }^{\mathrm{d}}$ Additionally adjusted for baseline morbidity, including diabetes, hypertension, hypercholesterolemia, cardiovascular disease, cancer, and musculoskeletal disease

\section{Magnesium intake and physical performance}

Our results are in line with those from the single randomized controlled trial conducted to the date that investigated if $\mathrm{Mg}$ supplementation improves physical performance. Veronese et al. [7] recruited 124 healthy women $>65$ years attending to a mild fitness program, and then compared with a group than received supplementation with $300 \mathrm{mg} / \mathrm{d}$ of bioavailable $\mathrm{Mg}$ with a placebo group. After 12 weeks, women from the treatment group experienced a significant increment of 0.41 points in the SPPB score, compared to women under placebo. In our study, women in tertile 3 of change in $\mathrm{Mg}$ intake achieved even larger positive changes in the SPPB score over 5 years (0.98 points). Previously, Lukaski et al. [21] had examined the effects of $\mathrm{Mg}$ depletion induced by dietary restriction on physiologic responses during submaximal exercise in ten postmenopausal middle-aged women (45-71 years old). They found that women fed with 180 versus $320 \mathrm{mg} / \mathrm{d}$ had worse cardiovascular function during submaximal work, supporting the current RDA for Mg. Moreover, findings from previous observational research are in the same direction. Two large studies with the EPIC-Norfolk and the UK-Biobank cohorts, found a clear cross-sectional positive dose-response between $\mathrm{Mg}$ intake and muscle mass
$[22,23]$, which is a strong determinant of physical performance. Other studies have also shown that sarcopenic older adults consumed less Mg than non-sarcopenic ones [24, 25].

Nevertheless, serum $\mathrm{Mg}$ does not seem to correlate well with $\mathrm{Mg}$ intakes [6]. Indeed, supplementation with dietary $\mathrm{Mg}$ increases serum Mg only among subjects with low basal circulating $\mathrm{Mg}$ [26]. This is consistent with our study findings. On one hand, the positive effects of dietary $\mathrm{Mg}$ were particularly observed in women moving from baseline low levels of intake to an appropriate $\mathrm{Mg}$ intake at the end of follow-up (i.e. above EAR or RDA). On the other hand, we found that participants reducing Mg intake during follow-up preserved physical performance if they continued to meet with dietary reference intake, suggesting that supplementation with $\mathrm{Mg}$ or dietary modifications to increase serum $\mathrm{Mg}$ are only necessary when older adults consume Mg bellow EAR or RDA.

The mechanisms of the effect of $\mathrm{Mg}$ on muscle mass or function are only partially known. Dietary Mg regulates some key mechanisms of muscle function, including protein and ATP synthesis, glycogenolysis, fatty acid oxidation, oxygen consumption and electrolyte balance [4]. It has also been postulated that oxidative stress and alterations in calcium homeostasis triggered by $\mathrm{Mg}$ reductions 
Table 3 Changes in the SPPB score (95\% confidence interval) between 2012 and 2017 according to compliance with the US dietary reference intake for magnesium between 2012 and 2017, overall and by sex

\begin{tabular}{|c|c|c|c|c|}
\hline & $\begin{array}{l}\text { Consistent non-com- } \\
\text { pliance }^{\mathrm{a}}\end{array}$ & $\begin{array}{l}\text { From non-compliance to } \\
\text { compliance }^{\mathrm{a}}\end{array}$ & $\begin{array}{l}\text { From compliance to non- } \\
\text { compliance }^{\mathrm{a}}\end{array}$ & Consistent compliance ${ }^{\mathrm{a}}$ \\
\hline \multicolumn{5}{|c|}{ Estimated average requirement } \\
\hline \multicolumn{5}{|l|}{ Overall } \\
\hline Participants, $n(\%)$ & $235(27.2)$ & $131(15.2)$ & $201(23.3)$ & $296(34.3)$ \\
\hline Mean change, $g / d$ & $-21.4(42.5)$ & $50.1(65.4)$ & $-68.7(67.4)$ & $-34.8(99.2)$ \\
\hline Multivariable model $^{\mathrm{b}}$ & Ref & $0.46(-0.01 ; 0.92)$ & $-0.42(-0.83 ;-0.01)$ & $0.08(-0.30 ; 0.46)$ \\
\hline \multicolumn{5}{|l|}{ Women } \\
\hline Participants, $n(\%)$ & $67(15.3)$ & $62(14.1)$ & $101(23.0)$ & 209 (47.6) \\
\hline Mean change, g/d & $-34.1(38.0)$ & $36.6(58.7)$ & $-76.4(70.0)$ & $-44.9(102.4)$ \\
\hline Multivariable model $^{\mathrm{b}}$ & Ref & $1.14(0.36 ; 1.92)$ & $-0.12(-0.82 ; 0.58)$ & $0.55(-0.07 ; 1.18)$ \\
\hline \multicolumn{5}{|l|}{ Men } \\
\hline Participants, $n(\%)$ & $168(39.6)$ & $69(16.3)$ & $100(23.6)$ & $87(20.5)$ \\
\hline Mean change, g/d & $-16.4(43.2)$ & $62.2(69.0)$ & $-60.9(64.1)$ & $-10.5(86.7)$ \\
\hline Multivariable model $^{\mathrm{c}}$ & Ref & $0.06(-0.54 ; 0.67)$ & $-0.33(-0.86 ; 0.21)$ & $0.04(-0.51 ; 0.61)$ \\
\hline \multicolumn{5}{|c|}{ Recommended dietary allowance } \\
\hline \multicolumn{5}{|l|}{ Overall } \\
\hline Participants, $n(\%)$ & $494(57.2)$ & $101(11.7)$ & $155(18.0)$ & $113(13.1)$ \\
\hline Mean change, $g / d$ & $-17.3(51.1)$ & $66.1(67.4)$ & $-104.3(93.5)$ & $-40.3(93.7)$ \\
\hline Multivariable model $^{\mathrm{b}}$ & Ref & $0.45(-0.02 ; 0.91)$ & $0.07(-0.33 ; 0.47)$ & $-0.07(-0.51 ; 0.38)$ \\
\hline \multicolumn{5}{|l|}{ Women } \\
\hline Participants, $n(\%)$ & $184(41.9)$ & $68(15.5)$ & $102(23.2)$ & $85(19.4)$ \\
\hline Mean change, g/d & $-29.3(42.2)$ & $52.8(62.0)$ & $-112(100.5)$ & $-46.0(94.1)$ \\
\hline Multivariable model $^{\mathrm{b}}$ & Ref & $0.84(0.22 ; 1.47)$ & $0.19(-0.37 ; 0.74)$ & $0.34(-0.25 ; 0.93)$ \\
\hline \multicolumn{5}{|l|}{ Men } \\
\hline Participants, $n(\%)$ & $310(73.3)$ & $33(7.80)$ & $53(12.5)$ & $28(6.60)$ \\
\hline Mean change, g/d & $-10.2(54.5)$ & $93.7(71.1)$ & $-89.6(77.1)$ & $-23.0(92.2)$ \\
\hline Multivariable model $^{\mathrm{b}}$ & Ref & $0.02(-0.75 ; 0.79)$ & $0.13(-0.49 ; 0.76)$ & $-0.28(-1.10 ; 0.55)$ \\
\hline
\end{tabular}

SPPB Short Physical Performance Battery test

${ }^{a}$ Cut-off points for recommendations compliance were $\geq 350 \mathrm{mg} / \mathrm{d}$ (women) and $\geq 265 \mathrm{mg} / \mathrm{d}$ (men) for Estimated Average Requirement, and $\geq 420 \mathrm{mg} / \mathrm{d}$ (women) and $\geq 320 \mathrm{mg} / \mathrm{d}$ (men) for Recommended Dietary Allowance

${ }^{\mathrm{b}}$ Adjusted for baseline SPPB score (tertiles of score), age $(<70,70-79, \geq 80 \mathrm{y})$, educational level (primary, secondary, university) and physical activity (tertiles of METs-h/w), smoking status (current, former, never), BMI (tertiles of $\mathrm{kg} / \mathrm{m}^{2}$ ), TV-watching (tertiles of h/wk) and alcohol intake (tertiles of $\mathrm{g} / \mathrm{d}$ )

can lead to muscle cells damage [27-29]. Furthermore, $\mathrm{Mg}$ may exert certain protection against inflammation, which has been associated with an acceleration of age-related loss of skeletal muscle [4, 28, 29]. Moreover, $\mathrm{Mg}$ stimulates the process of bone development and mineralization through several mechanisms [28], and there is strong evidence of the positive role of $\mathrm{Mg}$ on fracture risk reduction and on bone mineral density [29], which is essential for physical performance [30]. Lastly, results from a recent analysis of US National Health and Nutrition Examination Survey (NHANES) suggested that high Mg intake may have a positive role in cognitive function [31]; thereby, physical performance improvement could be parallel to cognitive impairment prevention.

\section{Sex differences}

The reasons why in our study women but not men benefited from an increase in $\mathrm{Mg}$ intake are unknown but could be related to biological differences between sexes. First, there is some evidence of the beneficial effect of $\mathrm{Mg}$ on several highly prevalent chronic morbid conditions, such as cardiovascular disease or type 2 diabetes [32-34], which are also associated to physical performance [35, 36]. Given that the positive effects of $\mathrm{Mg}$ on cardiometabolic health seem to be greater among women [32, 33], our results could partially be due to beneficial effect of $\mathrm{Mg}$ preventing the development of cardiovascular diseases and type 2 diabetes. Indeed, in our sample, the prevalence 
of these diseases in women were lower than in men. Second, postmenopausal women are affected more often than men from musculoskeletal disorders and sarcopenia [37, 38]. These health conditions, specially osteoporosis, lead to an imbalance in bone deposition and resorption, altering the serum $\mathrm{Mg}$ level and making subjects more sensitive to dietary supplements $[38,39]$. This is consistent with our findings from stratified analyses, as the observed effect of $\mathrm{Mg}$ intake on physical performance tended to be stronger among women with musculoskeletal diseases. Third, Mg is potentially important for the metabolism of anabolic-androgenic steroids and other sex hormones during aging, such as testosterone, progesterone and insulin-like growth factor 1 [40]. Some studies conducted only with men have found that $\mathrm{Mg}$ acts on the muscle via the endocrine system [41]. Given that the levels of these hormones are sex-dependent, it can be expected that the effects of $\mathrm{Mg}$ intake on muscle differ between sexes. Nevertheless, given that hormonal decline is steep during ageing, the endocrine pathway would be more plausible among younger subjects. More research is clearly needed to understand why dietary $\mathrm{Mg}$ intake improves physical performance only in women and, from a broader perspective, to understand the suggested sex-dependent effects of $\mathrm{Mg}$ intake on healthy ageing [39, 42].

\section{Practical implications}

In our longitudinal study, an overall reduction in $\mathrm{Mg}$ intake was observed, even among those who were consistently compliant with dietary recommendations. It seems clear that the risk of $\mathrm{Mg}$ deficiency is hanging over most of the people during aging process. Therefore, it could be advised a periodically assessment of available $\mathrm{Mg}$ to early detect older adults moving to levels below the recommended Mg thresholds. However, there are still no valid and simple methods to determine the available $\mathrm{Mg}$. For instance, serum $\mathrm{Mg}$ only represents $1 \%$ of total body magnesium, which is mainly intracellular $[6,43]$. Thereby, clinical assessment of patients at risk for $\mathrm{Mg}$ deficiency could be actually recommended, which may include the routine evaluation of $\mathrm{Mg}$ intake. Given that it is unrealistic to ask clinicians to perform a complete diet history to estimate $\mathrm{Mg}$ intake, they could be requested to inquire and counsel about the consumption of main food sources $\mathrm{Mg}$. These sources include foods who are usually part of most healthy diet patterns, such as whole grain cereals, vegetables, nuts, and legumes [43]. For instance, in our cohort of Spanish older adults, main sources of $\mathrm{Mg}$ were cereals, dairy products and nuts. Conversely, ultra-processed foods, which are predominant in the Western diet, are normally poor in $\mathrm{Mg}$ [43].

\section{Strengths and limitations}

Among the strengths of our study is a rather large sample size, a long follow-up that allows to detect substantial changes in physical performance, and a separate data analyses in men and women. Also, we used a validated diet history to ascertain changes in $\mathrm{Mg}$ dietary intake across the follow-up period. Lastly, statistical analyses were adjusted for a good number of potential confounders and included several sensitivity analyses to provide robustness. Nevertheless, this study also has some limitations. First, as in any nutritional epidemiological study, there could be some recall bias; however, this type of bias usually tends to underestimate study associations. Second, although having information on serum Mg levels would have been desirable, studies have shown a lack of correlation between $\mathrm{Mg}$ intake and its serum levels suggesting that the latter should not be used to predict disease risk [44]. Third, although we used musculoskeletal disorders as a proxy of bone health, we lacked data about osteoporosis, which is closely related to minerals and physical performance. Finally, despite the prospective nature of the study reverse causality cannot completely be ruled out, since participants might have first experimented a deterioration in physically performance and later, a decrease in their capacity to buy and cook a healthy diet with the appropriate amount of magnesium. Nevertheless, if this was the actual direction of causality, we would have expected the same results for women and men.

\section{Conclusions}

An increase of dietary $\mathrm{Mg}$ intake was prospectively associated with better physical performance in older women. Adhering to reference $\mathrm{Mg}$ intake in the old age could help women to maintain physical functioning and delay the disability process. Further studies are needed to confirm and understand why this association might occur exclusively in women.

Supplementary Information The online version contains supplementary material available at https://doi.org/10.1007/s00394-022-02808-z.

Acknowledgements This work was supported by grants from the Instituto de Salud Carlos III, State Secretary of R+D+I of Spain and FEDER/FSE (FIS 20/140), the European Union (FP7-HEALTH2012-Proposal No: 305483-2, FRAILOMIC Initiative), the ATHLOS project (EU H2020_-Project ID: 635316).

Author contributions All authors contributed to the study conception and design. LA-F: data curation; formal analysis; writing-original draft; validation. EAS: data curation; software; writing-review and editing. FFC: data curation; software; writing — review and editing. RO: data curation; software; writing - review and editing. EG-E: data curation; software; writing — review and editing. FR-A: funding acquisition; project administration; resources; writing - review and editing. EL-G; funding acquisition; supervision; investigation; methodology; 
validation; writing - review and editing. AL: supervision; investigation; methodology; validation; formal analysis; writing—original draft.

Funding Open Access funding provided thanks to the CRUE-CSIC agreement with Springer Nature. This work was supported by grants from the Instituto de Salud Carlos III, State Secretary of R + D + I of Spain and FEDER/FSE (FIS 13/0288, 16/609 and 16/1512), the European Union (FP7-HEALTH-2012-Proposal No: 305483-2, FRAILOMIC Initiative), the ATHLOS project (EU H2020_Project ID: 635316).

Availability of data and materials Lucía Arias-Fernández, Ellen A Struijk, Francisco Félix Caballero, Rosario Ortolá, Esther GarcíaEsquinas, Fernando Rodríguez-Artalejo, Esther Lopez-Garcia, and Alberto Lana comply with the Ethical guidelines for authorship and publishing in the European Journal of Nutrition.

Code availability Not applicable.

\section{Declarations}

Conflict of interest Lucía Arias-Fernández, Ellen A Struijk, Francisco Félix Caballero, Rosario Ortolá, Esther García-Esquinas, Fernando Rodríguez-Artalejo, Esther Lopez-Garcia, and Alberto Lana declare no conflict of interest.

Ethics approval The Seniors-ENRICA cohort was approved by the Clinical Research Ethics Committee of the $\mathrm{La} \mathrm{Paz}$ University Hospital in Madrid and has been performed in accordance with the ethical standards laid down in the 1964 Declaration of Helsinki and its later amendments.

Consent to participate Written informed consent was given by all study participants prior to their inclusion in the study.

Consent for publication All authors agree the content to be submitted and to be accountable for all aspects of the work in ensuring that questions related to the accuracy or integrity of any part of the work are appropriately investigated and resolved.

Open Access This article is licensed under a Creative Commons Attribution 4.0 International License, which permits use, sharing, adaptation, distribution and reproduction in any medium or format, as long as you give appropriate credit to the original author(s) and the source, provide a link to the Creative Commons licence, and indicate if changes were made. The images or other third party material in this article are included in the article's Creative Commons licence, unless indicated otherwise in a credit line to the material. If material is not included in the article's Creative Commons licence and your intended use is not permitted by statutory regulation or exceeds the permitted use, you will need to obtain permission directly from the copyright holder. To view a copy of this licence, visit http://creativecommons.org/licenses/by/4.0/.

\section{References}

1. Barbagallo M, Veronese N, Dominguez LJ (2021) Magnesium in aging, health and diseases. Nutrients 13:463. https://doi.org/10. 3390/nu13020463
2. Killilea DW, Maier JA (2008) A connection between magnesium deficiency and aging: new insights from cellular studies. Magnes Res 21:77-82

3. Wang R, Chen C, Liu W et al (2017) The effect of magnesium supplementation on muscle fitness: a meta-analysis and systematic review. Magnes Res 30:120-132. https://doi.org/10.1684/mrh. 2018.0430

4. Perna S, Alalwan TA, Al-Thawadi S et al (2020) Evidence-based role of nutrients and antioxidants for chronic pain management in musculoskeletal frailty and sarcopenia in aging. Geriatrics (Basel) 5:16. https://doi.org/10.3390/geriatrics5010016

5. Dominguez LJ, Barbagallo M, Lauretani F et al (2006) Magnesium and muscle performance in older persons: the InCHIANTI study. Am J Clin Nutr 84:419-426. https://doi.org/10.1093/ajen/ 84.1.419

6. van Dam RM (2020) Serum magnesium and risk of coronary artery disease: are there implications for dietary interventions? Am J Clin Nutr 111:6-7. https://doi.org/10.1093/ajen/nqz289

7. Veronese N, Berton L, Carraro S et al (2014) Effect of oral magnesium supplementation on physical performance in healthy elderly women involved in a weekly exercise program: a randomized controlled trial. Am J Clin Nutr 100:974-981. https://doi.org/10.3945/ ajen.113.080168

8. Asamane EA, Greig CA, Thompson JL (2020) The association between nutrient intake, nutritional status and physical function of community-dwelling ethnically diverse older adults. BMC Nutr 6:36. https://doi.org/10.1186/s40795-020-00363-6

9. Rude RK, Singer FR, Gruber HE (2009) Skeletal and hormonal effects of magnesium deficiency. J Am Coll Nutr 28:131-141. https://doi.org/10.1080/07315724.2009.10719764

10. Rodríguez-Artalejo F, Graciani A, Guallar-Castilón P et al (2011) Rationale and methods of the study on nutrition and cardiovascular risk in Spain (ENRICA). Rev Esp Cardiol 64:876-682. https:// doi.org/10.1016/j.recesp.2011.05.019

11. Lana A, Struijk EA, Ortolá R, Rodríguez-Artalejo F, Lopez-Garcia E (2020) Longitudinal association between sodium and potassium intake and physical performance in older adults. J Gerontol A Biol Sci Med Sci 75:2379-2386. https://doi.org/10.1093/gerona/glaa0 31

12. Guralnik JM, Ferrucci L, Pieper CF et al (2000) Lower extremity function and subsequent disability: consistency across studies, predictive models, and value of gait speed alone compared with the short physical performance battery. J Gerontol A Biol Sci Med Sci 55:M221-231. https://doi.org/10.1093/gerona/55.4.m221

13. Guallar-Castillón P, Sagardui-Villamor J, Balboa-Castillo T et al (2014) Validity and reproducibility of a Spanish dietary history. PLoS ONE 9:e86074. https://doi.org/10.1371/journal.pone.00860 74

14. Moreiras O, Carvajal A, Cabrera L, Cuadrado C (2007) Tablas de composición de alimentos, 11th edn. Ediciones Pirámide, Madrid

15. Van Dam RM (2012) Biochemical indicators of dietary intake. In: Willet WC (ed) Nutritional epidemiology, 3rd edn. Oxford University Press, Oxford

16. Pols MA, Peeters PH, Ocké MC, Slimani B-d-M, Collette HJ (1997) Estimation of reproducibility and relative validity of the questions included in the EPIC physical activity questionnaire. Int J Epidemiol 26:S181-189. https://doi.org/10.1093/ije/26.suppl_1. s181

17. American Diabetes Association (2014) Diagnosis and classification of diabetes mellitus. Diabetes Care 37(Suppl 1):S81-90. https://doi.org/10.2337/dc14-S081

18. Banegas JR, Graciani A, de la Cruz-Troca JJ et al (2012) Achievement of cardiometabolic goals in aware hypertensive patients in Spain: a nationwide population-based study. Hypertension 60:898-905. https://doi.org/10.1161/HYPERTENSIONAHA. 112.193078 
19. Institute of Medicine (US) Standing Committee on the Scientific Evaluation of Dietary Reference Intakes (1997) Dietary reference intakes for calcium, phosphorus, magnesium, vitamin $\mathrm{D}$, and fluoride. National Academies Press, Washington (DC)

20. Panel on Dietetic Products Nutrition and Allergies (2015) Scientific opinion on dietary reference values for magnesium. EFSA $J$ 13:4186. https://doi.org/10.2903/j.efsa.2015.4186

21. Lukaski HC, Nielsen FH (2002) Dietary magnesium depletion affects metabolic responses during submaximal exercise in postmenopausal women. J Nutr 132:930-935. https://doi.org/10.1093/ jn/132.5.930

22. Hayhoe RPG, Lentjes MAH, Mulligan AA, Luben RN, Khaw KT, Welch AA (2019) Cross-sectional associations of dietary and circulating magnesium with skeletal muscle mass in the EPICNorfolk cohort. Clin Nutr 38:317-323. https://doi.org/10.1016/j. clnu.2018.01.014

23. Welch AA, Skinner J, Hickson M (2017) Dietary magnesium may be protective for aging of bone and skeletal muscle in middle and younger older age men and women: cross-sectional findings from the UK biobank cohort. Nutrients 9:E1189. https://doi.org/ 10.3390/nu9111189

24. Ter Borg S, de Groot LC, Mijnarends DM et al (2016) Differences in nutrient intake and biochemical nutrient status between sarcopenic and nonsarcopenic older adults-results from the maastricht sarcopenia study. J Am Med Dir Assoc 17:393-401. https://doi. org/10.1016/j.jamda.2015.12.015

25. Verlaan S, Aspray TJ, Bauer JM et al (2017) Nutritional status, body composition, and quality of life in community-dwelling sarcopenic and non-sarcopenic older adults: a case-control study. Clin Nutr 36:267-274. https://doi.org/10.1016/j.clnu.2015.11.013

26. Zhang X, Del Gobbo LC, Hruby A et al (2016) The circulating concentration and 24-h urine excretion of magnesium dose- and time-dependently respond to oral magnesium supplementation in a meta-analysis of randomized controlled trials. J Nutr 146:595602. https://doi.org/10.3945/jn.115.223453

27. Furutani Y, Funaba M, Matsui T (2011) Magnesium deficiency up-regulates Myod expression in rat skeletal muscle and $\mathrm{C} 2 \mathrm{C} 12$ myogenic cells. Cell Biochem Funct 29:577-581. https://doi.org/ $10.1002 /$ cbf. 1790

28. Ciosek Ż, Kot K, Kosik-Bogacka D, Łanocha-Arendarczyk N, Rotter I (2021) The effects of calcium, magnesium, phosphorus, fluoride, and lead on bone tissue. Biomolecules 11:506. https:// doi.org/10.3390/biom11040506

29. Rondanelli M, Faliva MA, Tartara A et al (2021) An update on magnesium and bone health. Biometals 34:715-736. https://doi. org/10.1007/s 10534-021-00305-0

30. Unocc CP, Valdez LI, Segura ER (2015) A critical appraisal on the association and effects of magnesium and bone density on physical performance in elderly women. Am J Clin Nutr 101:889. https://doi.org/10.3945/ajcn.114.100677

31. Peeri NC, Egan KM, Chai W, Tao MH (2021) Association of magnesium intake and vitamin $\mathrm{D}$ status with cognitive function in older adults: an analysis of US National Health and Nutrition Examination Survey (NHANES) 2011 to 2014. Eur J Nutr 60:465-474. https://doi.org/10.1007/s00394-020-02267-4

32. Rooney MR, Alonso A, Folsom AR et al (2020) Serum magnesium and the incidence of coronary artery disease over a median 27 years of follow-up in the atherosclerosis risk in communities (ARIC) study and a meta-analysis. Am J Clin Nutr 111:52-60. https://doi.org/10.1093/ajen/nqz256

33. Fang X, Han H, Li M et al (2016) Dose-response relationship between dietary magnesium intake and risk of type 2 diabetes mellitus: a systematic review and meta-regression analysis of prospective cohort studies. Nutrients 8:739. https://doi.org/10.3390/ nu8110739

34. Veronese N, Demurtas J, Pesolillo G et al (2020) Magnesium and health outcomes: an umbrella review of systematic reviews and meta-analyses of observational and intervention studies. Eur J Nutr 59:263-272. https://doi.org/10.1007/s00394-019-01905-w

35. Bellettiere J, Lamonte MJ, Unkart J et al (2020) Short physical performance battery and incident cardiovascular events among older women. J Am Heart Assoc 9:e016845. https://doi.org/10. 1161/JAHA.120.016845

36. Kang S, Oh TJ, Cho BL et al (2021) Sex differences in sarcopenia and frailty among community-dwelling Korean older adults with diabetes: the Korean frailty and aging cohort study. J Diabetes Investig 12:155-164. https://doi.org/10.1111/jdi.13348

37. Lin YJ, Anzaghe M, Schülke S (2020) Update on the pathomechanism, diagnosis, and treatment options for rheumatoid arthritis. Cells 9:880. https://doi.org/10.3390/cells9040880

38. Greco EA, Pietschmann P, Migliaccio S (2019) Osteoporosis and sarcopenia increase frailty syndrome in the elderly. Front Endocrinol (Lausanne) 10:255. https://doi.org/10.3389/fendo.2019. 00255

39. Veronese N, Stubbs B, Solmi M et al (2017) Dietary magnesium intake and fracture risk: data from a large prospective study. $\mathrm{Br} \mathrm{J}$ Nutr 117:1570-1576. https://doi.org/10.1017/S00071145170013 50

40. Janjuha R, Bunn D, Hayhoe R et al (2020) Effects of dietary or supplementary micronutrients on sex hormones and IGF-1 in middle and older age: a systematic review and meta-analysis. Nutrients 12:1457. https://doi.org/10.3390/nu12051457

41. Maggio M, Ceda GP, Lauretani F et al (2011) Magnesium and anabolic hormones in older men. Int J Androl 34:e594-600. https://doi.org/10.1111/j.1365-2605.2011.01193.x

42. Veronese N, Stubbs B, Maggi S et al (2017) Dietary magnesium and incident frailty in older people at risk for knee osteoarthritis: an eight-year longitudinal study. Nutrients 9:1253. https://doi.org/ $10.3390 /$ nu 9111253

43. Dominguez L, Veronese N, Barbagallo M (2020) Magnesium and hypertension in old age. Nutrients 13:139. https://doi.org/10.3390/ nu13010139

44. Razzaque MS (2018) Magnesium: are we consuming enough? Nutrients 10:1863. https://doi.org/10.3390/nu10121863 